\title{
Characterization of polypropylene-polyethylene blends by temperature rising elution and crystallization analysis fractionation
}

\author{
Benjamín Monrabal • Pilar del Hierro
}

Received: 4 June 2010 /Revised: 21 July 2010 / Accepted: 22 July 2010 / Published online: 22 August 2010

(C) The Author(s) 2010. This article is published with open access at Springerlink.com

\begin{abstract}
The introduction of single-site catalysts in the polyolefins industry opens new routes to design resins with improved performance through multicatalyst-multireactor processes. Physical combination of various polyolefin types in a secondary extrusion process is also a common practice to achieve new products with improved properties. The new resins have complex structures, especially in terms of composition distribution, and their characterization is not always an easy task. Techniques like temperature rising elution fractionation (TREF) or crystallization analysis fractionation (CRYSTAF) are currently used to characterize the composition distribution of these resins. It has been shown that certain combinations of polyolefins may result in equivocal results if only TREF or CRYSTAF is used separately for their characterization.
\end{abstract}

Keywords CRYSTAF. TREF. Polypropylene ·

Polyethylene $\cdot$ Fractionation of polymers

\section{Introduction}

The introduction of single-site catalysts in the polyolefins industry has opened new routes to design resins with desirable structures for improved performance in specific applications. The molecular weight and composition distribution are easily modified through multicatalyst-multireactor processes or

Published in the special issue on Separation Science of Macromolecules with Guest Editor André Striegel.

B. Monrabal $(\bowtie) \cdot$ P. del Hierro

Polymer Char S.A.,

Valencia Technology Park,

46980 Paterna, Spain

e-mail: benjamin.monrabal@polymerchar.com through the combination of copolymers produced from single-site and/or Ziegler-Natta catalysts in a sidearm extruder.

In the case of polypropylene copolymers, complex structures are being designed with modification of tacticity, with the presence of both polyethylene and polypropylene homopolymers, and with various contents of ethylenepropylene copolymers. On occasions, the presence of some of these components is an undesirable feature of the reaction process which needs to be controlled.

The characterization of these complex resins is not an easy task and requires a multidisciplinary approach to resolve the chemical and molar mass distribution, its interdependence, and the intramolecular uniformity of the various components. The use of high temperature interaction chromatography is being investigated these days with very promising results $[1,2]$ to separate polyethylene and various polypropylene types. Most of the characterization work is still being done through the analysis of the chemical composition distribution (CCD) by crystallization techniques which provide the most discrimination power. The CCD is typically measured by temperature rising elution fractionation (TREF) or by crystallization analysis fractionation (CRYSTAF) as discussed below.

\section{Principles of TREF and CRYSTAF}

The principles of TREF [3-6] and CRYSTAF [6, 7] have been discussed extensively in the literature. Both separation techniques share the same fundamental principles: samples are separated according to crystallizability. Separation occurs in dilute solution to reduce co-crystallization effects.

In CRYSTAF, the separation occurs in a stirred vessel during the crystallization step; the depletion of solution 
concentration is monitored to obtain the composition distribution and no physical fractions are obtained.

In TREF, separation occurs also in the crystallization process where crystal aggregates are deposited in layers on the support particles in a packed column. A second step of dissolution, the temperature rising elution cycle, is required to obtain fractions and the overall composition distribution.

A schematic diagram of the separation steps is shown in Fig. 1; although crystal segregation occurs in both CRYSTAF and TREF in the crystallization process, the data and fractions in TREF are obtained in the dissolution step (heating), whereas in CRYSTAF the data are obtained in the crystallization process itself (cooling).

The CCD curves obtained by both techniques are quite similar as shown in the analysis of a bimodal linear low density polyethylene (LLDPE) resin in Fig. 2. However, the difference in obtaining the fractionation information in the two techniques (heating versus cooling) results in a shift of the observed peak temperature due to polymer undercooling during crystallization from solution.

\section{Experimental}

CRYSTAF was performed in a model 200 instrument from Polymer Char S.A. Standard conditions were used in all the analyses with a starting solution concentration of $0.1 \%(\mathrm{w} / \mathrm{w})$, $30 \mathrm{mg}$ in $30 \mathrm{ml}$ of $1,2,4$ trichlorobenzene (TCB), and a crystallization rate of $0.1{ }^{\circ} \mathrm{C} / \mathrm{min}$. The description of the technique has been widely covered in past publications [6-8].

TREF was performed in an automated TREF-CRYSTAF model from Polymer Char S.A. This apparatus [8] is an extension of the CRYSTAF equipment with the addition of a high pressure pump, an injection valve, and the TREF column as shown in Fig. 3.

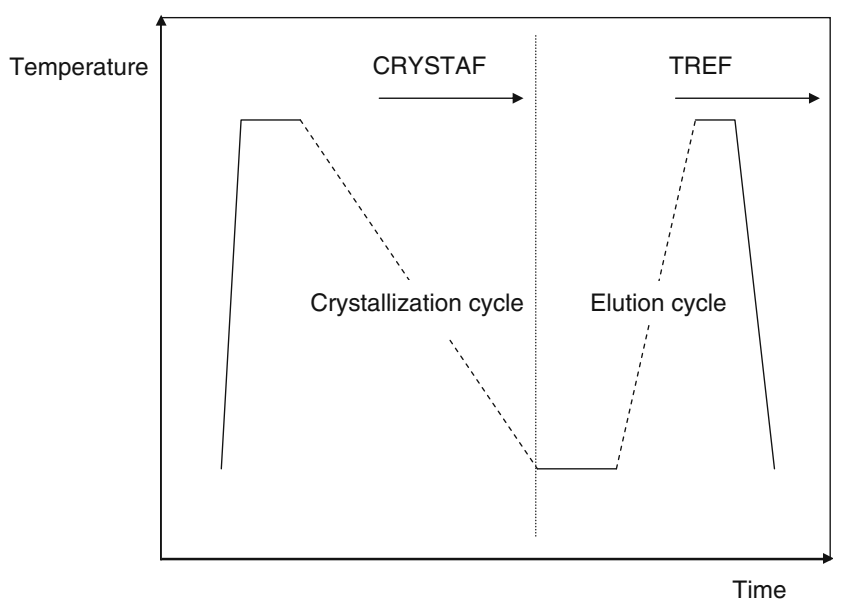

Fig. 1 Schematic diagram of CRYSTAF and TREF separation processes

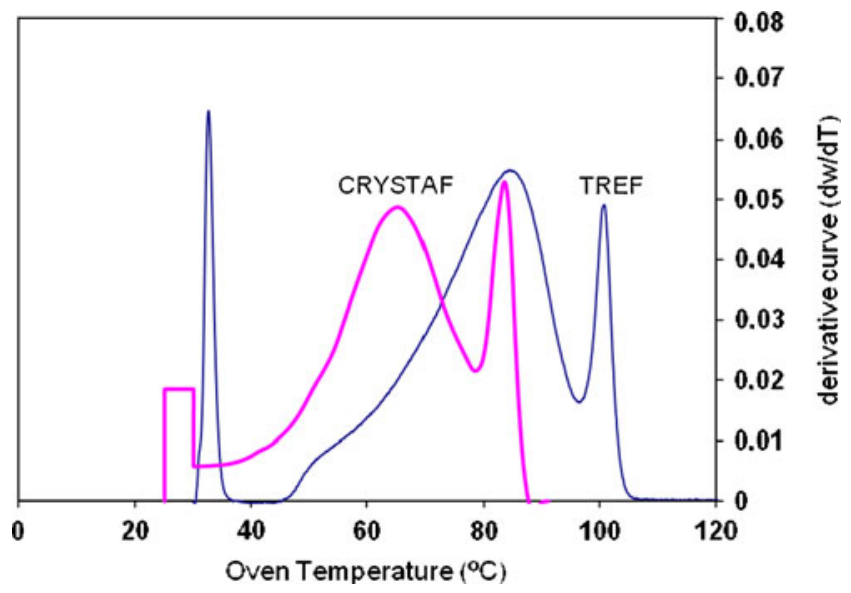

Fig. 2 Analysis of a bimodal LLDPE resin by TREF and CRYSTAF

The crystallization vessels of the original CRYSTAF part of the apparatus are used in the TREF mode for sample dissolution and filtration of up to five different samples.

The sample solution of the first vessel, typically $0.5 \mathrm{ml}$ with $2 \mathrm{mg}$ of polymer, is automatically loaded into a TREF column of $7.8-\mathrm{mm}$ i.d. and $10-\mathrm{cm}$ length. After crystallization at a preselected cooling rate, typically between 0.1 and $0.5{ }^{\circ} \mathrm{C} / \mathrm{min}$, the pump is switched on to start TCB flow through the column at $0.5 \mathrm{ml} / \mathrm{min}$; at the same time, heating of the column starts, at a rate typically between 1 and $4{ }^{\circ} \mathrm{C} /$ min, to obtain the TREF curve of the first sample. This process is repeated for the other four samples automatically without the need for operator intervention.

The description and properties of the polymers analyzed are shown in Table 1.

Blends of polypropylene (PP) and ethylene-propylene copolymer produced both by using Ziegler-Natta or metallocene catalysts with high density polyethylene homopolymer (PE) were obtained by melting known amounts in a hot press, cutting the film into small pieces, and hot-pressing them again to obtain a sample of uniform composition. Some of these blends were designed to cover a range of chemical composition that exists in commercial resins.

Redistilled TCB with the addition of 300 ppm of Irganox 1010 was used in all the experiments.

\section{Analysis of a blend of polypropylene and polyethylene homopolymers}

The dissolution temperature of polyethylene homopolymer in TREF with TCB as solvent is around $98{ }^{\circ} \mathrm{C}$, whereas the polypropylene homopolymer produced from a Ziegler-type catalyst dissolves at around $118{ }^{\circ} \mathrm{C}$. The TREF analysis of a blend of samples A and D does show a distinct difference in dissolution temperature of the PP and PE homopolymer peaks as shown in Fig. 4. 
Fig. 3 Schematic diagram of an automated TREF-CRYSTAF apparatus

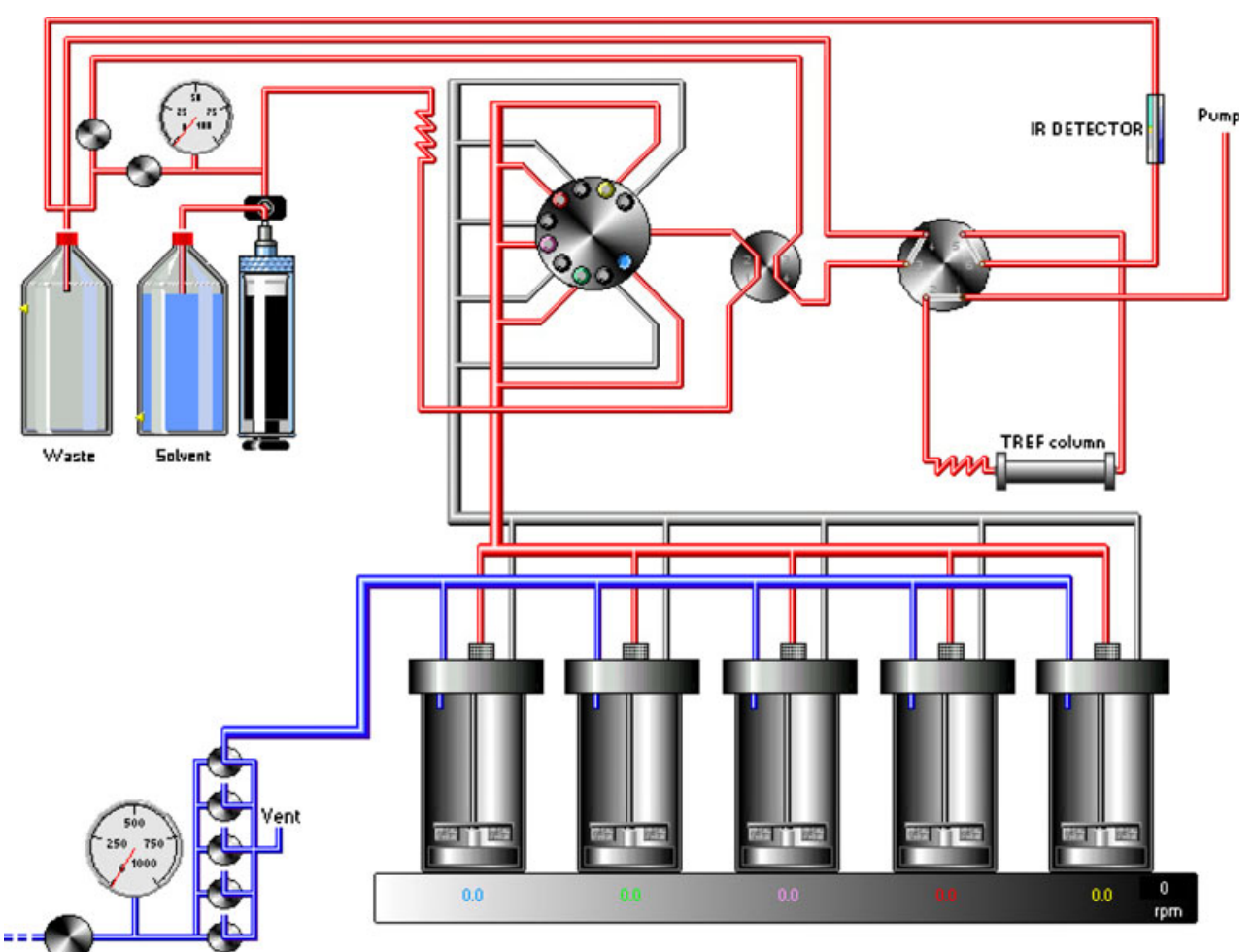

When measuring the crystallization temperature in solution by CRYSTAF, polyethylene results in an undercooling of around $13{ }^{\circ} \mathrm{C}$ as the peak appears at $85{ }^{\circ} \mathrm{C}$. Polypropylene, on the other hand, with a much higher undercooling (close to $40{ }^{\circ} \mathrm{C}$ ), crystallizes at around $80{ }^{\circ} \mathrm{C}$, i.e., now $5{ }^{\circ} \mathrm{C}$ below the crystallization temperature of polyethylene. The analysis of the blend A+D by CRYSTAF does not result in well-resolved homopolymer peaks as shown in Fig. 5.

\section{Analysis of ethylene-propylene copolymer and polyethylene blends}

In random ethylene-propylene copolymers (EP), the incorporation of ethylene into the polypropylene chain reduces the crystallinity and therefore causes both the crystallization and the dissolution temperatures to be lower than the one in the PP homopolymer. The TREF analysis of a blend of an $\mathrm{EP}$ and $\mathrm{PE}$ (samples $\mathrm{C}$ and D) is shown in Fig. 6, where the EP peak elutes at $102{ }^{\circ} \mathrm{C}$, very close to the $\mathrm{PE}$ homopolymer peak at $98{ }^{\circ} \mathrm{C}$. In this case TREF does not provide adequate resolution for this particular polymer combination.

When analyzing this blend by CRYSTAF the EP copolymer crystallizes at lower temperatures than the PP homopolymer resulting in further separation of EP from the PE peak. CRYSTAF provides close to baseline resolution of the components as shown in Fig. 7.

\section{Analysis of metallocene-produced polypropylene and polyethylene blends}

Polypropylene homopolymer produced with a metallocenetype catalyst has been shown [9] to result in more uniform

Table 1 Properties of the polymers analyzed

\begin{tabular}{llllll}
\hline Sample & Polymer type & Catalyst used & $M_{\mathrm{w}}(\mathrm{g} / \mathrm{mol})$ & $M_{\mathrm{w}} / M_{\mathrm{n}}$ & Ethylene $^{\mathrm{b}}(\mathrm{wt} . \%)$ \\
\hline $\mathrm{A}^{\mathrm{a}}$ & PP high impact & Ziegler-Natta & 230,000 & 4.1 & 0 \\
$\mathrm{~B}$ & PP homopolymer & Metallocene & 140,000 & 2.3 & 0 \\
$\mathrm{C}$ & Random EP copolymer & Ziegler-Natta & 113,000 & 3.8 & 12 \\
$\mathrm{D}$ & PE homopolymer & Ziegler-Natta & 62,000 & 3.5 & 100 \\
\hline
\end{tabular}

\footnotetext{
${ }^{\mathrm{a}}$ Sample A is an experimental high impact PP with a major portion of PP homopolymer and $14 \%$ of rubber content; in this investigation we disregard the rubber fraction which does not interfere in the separation process of the homopolymer fraction

${ }^{\mathrm{b}}$ The rubber fraction in samples $\mathrm{A}$ and $\mathrm{C}$ is not considered in this measurement
} 


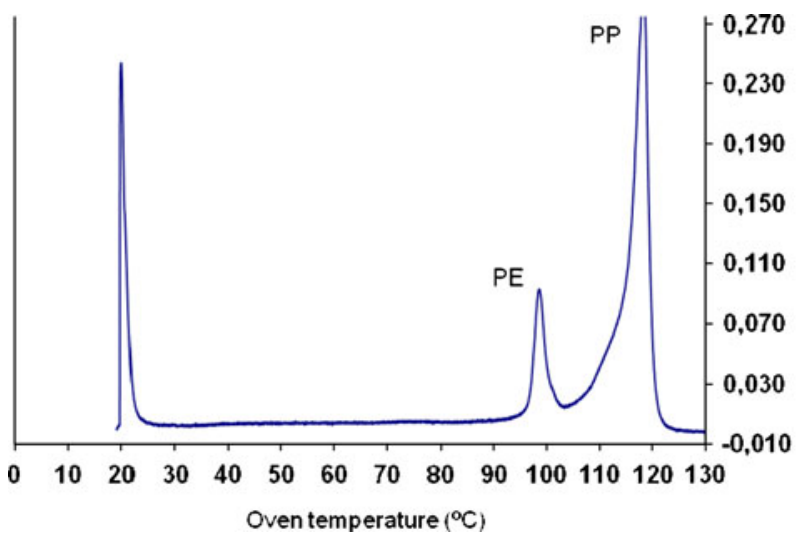

Fig. 4 TREF analysis of a polypropylene produced by using a Ziegler-Natta catalyst (sample A) in the presence of linear polyethylene homopolymer (sample D)

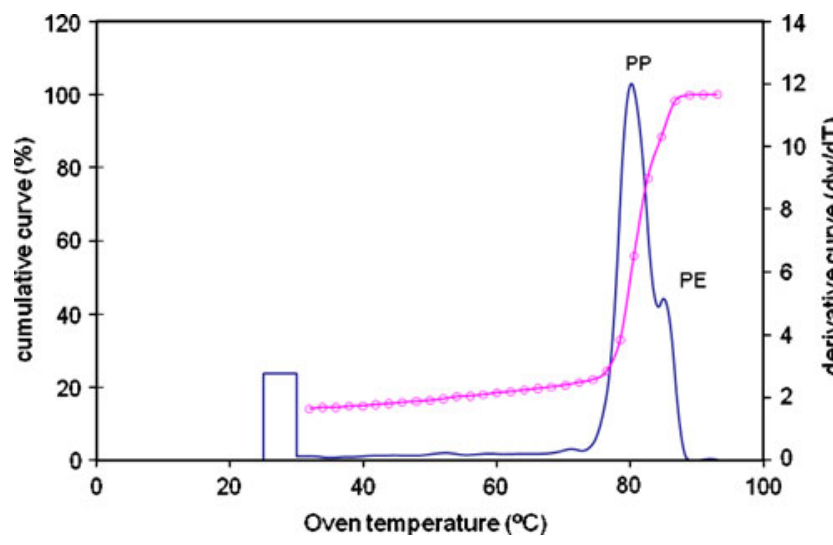

Fig. 5 CRYSTAF analysis of a polypropylene produced by using a Ziegler-Natta catalyst (sample A) in the presence of linear polyethylene homopolymer (sample D)

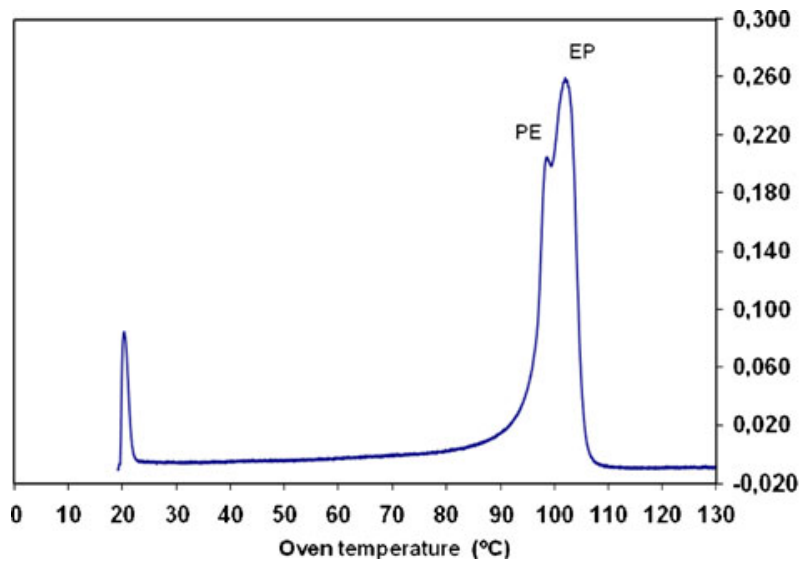

Fig. 6 TREF analysis of an EP copolymer produced by using a Ziegler-Natta catalyst (sample C) combined with a linear polyethylene homopolymer (sample D)

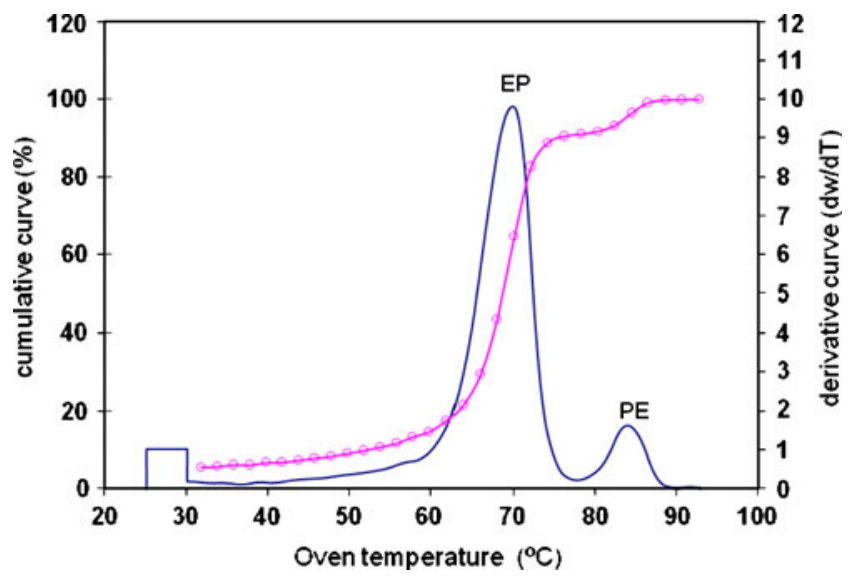

Fig. 7 CRYSTAF analysis of an EP copolymer produced by using a Ziegler-Natta catalyst (sample C) in the presence of linear polyethylene homopolymer (sample D)

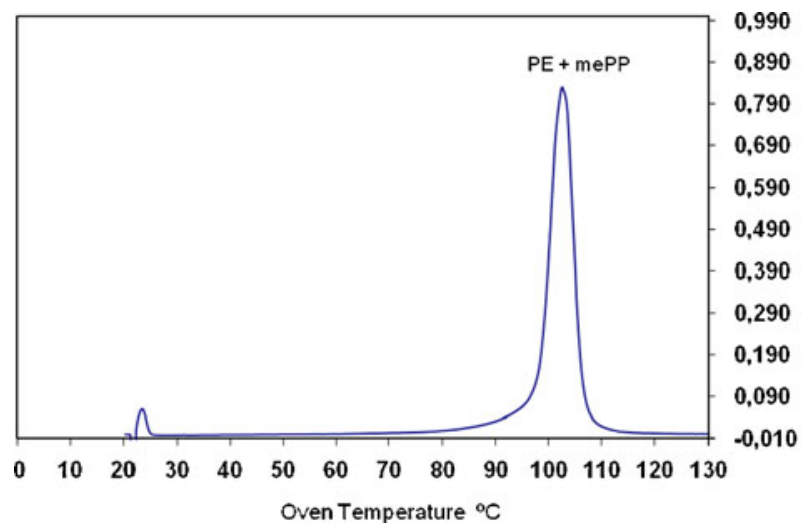

Fig. 8 TREF analysis of a polypropylene homopolymer produced by using a metallocene catalyst (sample B) combined with linear polyethylene homopolymer (sample D)

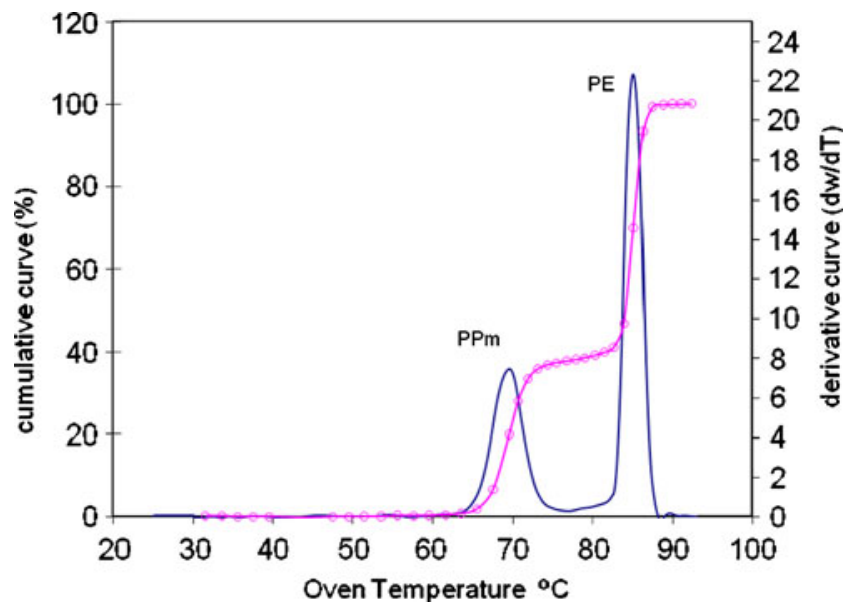

Fig. 9 CRYSTAF analysis of a polypropylene homopolymer produced by using a metallocene catalyst (sample B) combined with linear polyethylene homopolymer (sample D) 
chain to chain defect distribution although overall, and depending on the catalyst and process conditions, it may have a less regular structure than that produced with a Ziegler-Natta catalyst. Crystallization and dissolution temperatures in this case will be lower for the polypropylene produced by using a metallocene-type catalyst than for the polypropylene produced by using a ZieglerNatta-type catalyst. This has been observed by CRYSTAF and TREF.

The TREF analysis of a blend of metallocene-produced polypropylene homopolymer (sample B) with a linear polyethylene (sample D) is shown in Fig. 8. The polypropylene in this particular sample dissolves at around $102{ }^{\circ} \mathrm{C}$, so close to the $\mathrm{PE}$ temperature that only a single unresolved peak is observed in the analysis, very similar to the example above of the EP copolymer blend with PE.

When analyzing the same blend by CRYSTAF two peaks are obtained with baseline resolution as shown in Fig. 9. This is due to the fact that the polypropylene produced by using a metallocene-type catalyst crystallizes at significantly lower temperatures than polyethylene. This behavior is again very similar to the EP copolymer case mentioned before.

\section{Conclusions}

The large difference in undercooling between polypropylene and polyethylene may result in equivocal results when analyzing combinations of these polymers, depending on the technique being used, i.e., whether it is TREF or CRYSTAF.
TREF, which analyzes samples in the dissolution (melting) process, provides best resolution for combinations of highly regular isotactic polypropylene and polyethylene. CRYSTAF, which obtains the data during the crystallization process, is the preferred technique when analyzing combinations of polyethylene with ethylene-propylene copolymers or less regular polypropylene resins.

To obtain unequivocal results in the analysis of complex polypropylene and/or PE combinations both TREF and CRYSTAF must be considered.

Open Access This article is distributed under the terms of the Creative Commons Attribution Noncommercial License which permits any noncommercial use, distribution, and reproduction in any medium, provided the original author(s) and source are credited.

\section{References}

1. Heinz LC, Pasch H (2005) Polymer 46:12040-12045

2. Macko T, Pasch H (2009) Macromolecules 42:6063-6067

3. Wild L (1991) Adv Polym Sci 98:1-47

4. Soares JBP, Hamielec AE (1999) In: Pethrick RA (ed) Modern techniques for polymer characterization. Wiley, Chichester

5. Fonseca CA, Harrison IR (1999) In: Pethrick RA (ed) Modern techniques for polymer characterization. Wiley, Chichester

6. Monrabal B (2000) Encyclopedia of analytical chemistry. Wiley, New York

7. Monrabal B (1994) J Appl Polym Sci 52:491-499

8. Monrabal B (2000) Proceedings of the international GPC symposium, Las Vegas, 2000

9. Bond EB, Spruiell JE (1998) Metallocene catalyzed polymers. Soc Plast Eng 1:157-162 